\title{
The intracellular domain of cell adhesion molecule 1 is present in emphysematous lungs and induces lung epithelial cell apoptosis
}

Man Hagiyama ${ }^{1 \dagger}$, Azusa Yoneshige ${ }^{1 \dagger}$, Takao Inoue ${ }^{1}$, Yasufumi Sato ${ }^{1}$, Takahiro Mimae $^{2}$, Morihito Okada $^{2}$ and Akihiko Ito $^{1 *}$

\begin{abstract}
Background: Pulmonary emphysema is characterized histologically by destruction of alveolar walls and enlargement of air spaces due to lung epithelial cell apoptosis. Cell adhesion molecule 1 (CADM1) is an immunoglobulin superfamily member expressed in lung epithelial cells. CADM1 generates a membrane-associated C-terminal fragment, aCTF, through A disintegrin- and metalloprotease-10-mediated ectodomain shedding, subsequently releasing the intracellular domain (ICD) through $\gamma$-secretase-mediated intramembrane shedding of aCTF. aCTF localizes to mitochondria and induces apoptosis in lung epithelial cells. ACTF contributes to the development and progression of emphysema as a consequence of increased CADM1 ectodomain shedding. The purpose of this study was to examine whether the ICD makes a similar contribution.

Results: The ICD was synthesized as a 51-amino acid peptide, and its mutant was synthesized by substituting seven amino acids and deleting two amino acids. These peptides were labeled with fluorescein isothiocyanate and were introduced into various cell lines. ICD peptide-derived fluorescence was well visualized in lung epithelial cells at the site of Mitotracker mitochondrial labeling, but was detected in locations other than mitochondria in other cell types. Mutant peptide-derived fluorescence was detected in locations other than mitochondria, even in lung epithelial cells. Terminal deoxynucleotidyl transferase-mediated dUTP nick-end labeling assays revealed that transduction of the ICD peptide increased the proportion of apoptotic cells 2 - to 5 -fold in the lung epithelial cell lines, whereas the mutant peptide did not. Abundance of the ICD was below the Western blot detection limit in emphysematous $(n=4)$ and control $(n=4)$ human lungs. However, the ICD was detected only in emphysematous lungs when it was immunoprecipitated with anti-CADM1 antibody ( $4 / 4$ vs. 0/4, $P=0.029)$.
\end{abstract}

Conclusions: As the abundance of ICD molecules was sparse but present, increased CADM1 shedding appeared to contribute to the development of emphysema by generating aCTF and the ICD in lung epithelial cells.

Keywords: Mitochondrial apoptosis pathway, Protein transfection, $\gamma$-secretase, Shedding, Tumor suppressor in lung cancer 1 (TSLC1), Nectin-like molecule 2 (Necl-2)

\footnotetext{
* Correspondence: aito@med.kindai.ac.jp

${ }^{\dagger}$ Equal contributors

${ }^{1}$ Department of Pathology, Faculty of Medicine, Kinki University, Osaka

589-8511, Japan

Full list of author information is available at the end of the article
}

() Biomed Central

(c) 2015 Hagiyama et al. Open Access This article is distributed under the terms of the Creative Commons Attribution 4.0 International License (http://creativecommons.org/licenses/by/4.0), which permits unrestricted use, distribution, and reproduction in any medium, provided you give appropriate credit to the original author(s) and the source, provide a link to the Creative Commons license, and indicate if changes were made. The Creative Commons Public Domain Dedication waiver (http://creativecommons.org/publicdomain/zero/1.0/) applies to the data made available in this article, unless otherwise stated. 


\section{Background}

Pulmonary emphysema is a representative chronic obstructive pulmonary disease characterized by destruction of alveolar walls and enlargement of air spaces [1]. These histological characteristics evolve from alveolar and bronchiolar epithelial cell apoptosis and a local imbalance in protease over anti-protease activities [2, 3]. We recently found a molecular link between these two events by analyzing lung epithelial cell adhesion molecule 1 (CADM1), also known as tumor suppressor in lung cancer 1 (TSLC1) and nectin-like molecule 2 (Necl-2) [4]. CADM1 is an intercellular adhesion molecule in the immunoglobulin superfamily. This membrane-spanning glycoprotein is composed of three extracellular Ig-like domains, a single transmembrane region, and a short carboxy-terminal intracytoplasmic tail with a protein 4.1 interaction sequence (P4.1-IS) and a PDZ type II domain-binding motif (PDZ-BM) [5]. The major cell types that express CADM1 in the peripheral lung are bronchiolar and alveolar epithelial cells, but parenchymal lung mast cells and fibroblasts also express it $[6,7]$. CADM1 mediates not only lung epithelial cell-cell adhesion, but also lung mast cell adhesion to airway smooth muscle cells [6]. There are several splice isoforms of CADM1; the major ones are named SP1 to 4 [8]. The SP1 isoform reduces survival in HMC-1 mast cells and increases caspase 3/7 activity, whereas the SP4 isoform enhances survival and reduces caspase activity [9]. Recent studies show that CADM1 expression is regulated by post-transcriptional mechanisms, including glycosylation and proteolytic cleavage, referred to as shedding [10, 11]. CADM1 is cleaved at one of two sites in its ectodomain, yielding two membraneassociated C-terminal fragments, $\alpha$ CTF and $\beta$ CTF [4]. We found that CADM1 shedding increases in emphysematous lungs, and $\alpha \mathrm{CTF}$ contributes to apoptosis of lung epithelial cells by localizing in mitochondria [4]. A mutant form of $\alpha$ CTF ( $\alpha$ CTFmut) carrying amino acid substitutions and deletions in the intervening region between the P4.1-IS and the PDZ-BM did not localize to mitochondria, suggesting that the intervening region may carry the mitochondrial localization signal [4].

We showed previously that CADM1 $\alpha$ CTF is further cleaved by $\gamma$-secretase, an intramembrane-cleaving aspartyl protease, releasing the intracellular domain (ICD) into the cytosol [11]. Based on cleavage site specificity for $\gamma$-secretase, CADM1-ICD (C-ICD) is presumed to be a 51-amino acid peptide composed of the fulllength intracytoplasmic region (47 amino acids) with four amino acids extending into the transmembrane region toward the $\mathrm{N}$-terminus [11]. It is rather difficult to detect the presence of the C-ICD, probably because it is degraded rapidly, and many other ICD fragments generated by $\gamma$-secretase, including the ICD of Notch, a cell membrane-spanning receptor, are degraded rapidly in a proteasome-dependent manner $[12,13]$. Despite its low abundance, the Notch-ICD is important for transduction of intracellular signaling mediated by Notch [13].

The purpose of this study was to understand the biomedical relevance of the C-ICD. We first synthesized the C-ICD (51-amino acid peptide) and its mutant form (C-ICDmut; 49-amino acid peptide) carrying the same mutation as that of $\alpha C$ TFmut. We introduced the peptides into various cell lines including lung epithelial cells and examined whether the C-ICD localized to mitochondria and induced cell apoptosis. We next examined whether the C-ICD was present in emphysematous and control human lungs. The results showed that the C-ICD appeared to have actions similar to those of $\alpha \mathrm{CTF}$ in lung epithelial cells, thus contributing to the development of emphysema.

\section{Methods}

Cells

NCI-H441 cells (lot no. 58294188), a human lung epithelial cell line with characteristics of Clara cells, and RLE-6TN cells (lot no. 59111690), a rat lung epithelial cell line with characteristics of alveolar type II cells, were purchased from the American Type Culture Collection (Rockville, MD, USA) in 2010 and 2013, respectively. All experiments using these cells were performed within 4 months after resuscitation. NCI-H441 cells were grown as described in our previous report [4]. RLE-6TN cells were grown in Ham's F12 medium containing 2 mM L-glutamine (Gibco, Carlsbad, CA, USA) supplemented with $10 \%$ fetal bovine serum, $10 \mu \mathrm{g} / \mathrm{ml}$ bovine pituitary extract (PromoCell, Heidelberg, Germany), $5 \mu \mathrm{g} / \mathrm{ml}$ insulin (Gibco), $2.5 \mathrm{ng} / \mathrm{ml}$ insulin-like growth factor (Sigma-Aldrich, St. Louis, MO, USA), $1.25 \mu \mathrm{g} / \mathrm{ml}$ transferrin (Gibco), and $2.5 \mathrm{ng} / \mathrm{ml}$ epidermal growth factor (Sigma-Aldrich, St. Louis, MO, USA). COS7 and NIH3T3 cells were described previously $[14,15]$. COS7 cells that overexpressed CADM1 exogenously were described previously [11].

\section{Antibodies and reagents}

A rabbit anti-CADM1 polyclonal antibody directed against the C-terminal 15 -amino acid peptide was generated in our laboratory as described previously [16]. Other primary antibodies targeting fluorescein isothiocyanate (FITC) (Ab19224; Abcam, Cambridge, UK) and $\beta$-actin (mouse monoclonal AC-15; Sigma-Aldrich) were used. Peroxidase- and fluorophore-conjugated secondary antibodies were obtained from Amersham (Buckinghamshire, UK) and Jackson ImmunoResearch (West Grove, PA, USA), respectively. 4,6'-Diamidino-2phenylindole (DAPI; Dojindo, Kumakoto, Japan) and silver stain reagents (Sigma-Aldrich) were used according to the 
manufacturer's instructions. Phorbol 12-myristate 13acetate (PMA) was used as described previously [11].

\section{Peptide synthesis and FITC labeling}

The C-ICD and C-ICDmut peptides were synthesized by Fmoc chemistry using the PSSM-8 automated peptide synthesizer (Shimadzu, Kyoto, Japan) and purified by reverse-phase high-performance liquid chromatography on a $\mathrm{C} 18$ column with a linear gradient from 0 to $90 \%$ $\mathrm{CH}_{3} \mathrm{CN}$ in $0.1 \%$ trifluoroacetic acid for $60 \mathrm{~min}$ at a flow rate of $1 \mathrm{ml} / \mathrm{min}$. The purified peptides were digested with trypsin and separated using the Smart System (GE Healthcare, Little Chalfont, UK) on a RP300 column with a linear gradient from 0 to $90 \% \mathrm{CH}_{3} \mathrm{CN}$ in $0.1 \%$ trifluoroacetic acid for $50 \mathrm{~min}$ at a flow rate of $1 \mathrm{ml} /$ min, and the fractions were collected. The individual fractions were analyzed by matrix-assisted laser desorption/ionization time-of-flight collision-induced dissociation tandem mass spectroscopy using the Axima Performance system (Shimadzu), and their amino acid sequences were confirmed by the $492 \mathrm{HT}$ protein sequencer (Applied Biosystems, Foster City, CA, USA). FITC-I (Dojindo) was used to label the peptides according to the manufacturer's instructions. Briefly, the peptide and FITC-I were mixed at a weight ratio of 10:1 in phosphate-buffered saline (PBS) containing $2.5 \mathrm{mM}$ carbonate and were reacted at $4{ }^{\circ} \mathrm{C}$ for $4 \mathrm{~h}$. The FITClabeled peptide was washed with PBS by five centrifugation cycles using an Amicon Ultra-10 K membrane filter (Millipore, Billerica, MA, USA).

\section{Peptide transduction}

The Xfect Protein Transfection kit (Takara Bio Inc., Shiga, Japan) was used to introduce the peptides into cells according to the manufacturer's instructions. Briefly, cells were grown to 60-70\% confluence in coverslip-likebottomed 35-mm diameter culture dishes ( $\mu$-Dishes; ibidi, Verona, WI, USA) and incubated at $4{ }^{\circ} \mathrm{C}$ for $1 \mathrm{~h}$ in serumfree medium supplemented with $0.25 \times$ Xfect protein transfection reagent containing $0.4 \mu \mathrm{g}$ (for RLE-6TN cells) or $0.2 \mu \mathrm{g}$ (for the other cells) of either the C-ICD or C-ICDmut peptide labeled with FITC or unlabeled, as indicated. The cells were washed with serum-free medium and incubated in growth medium. The same treatment was applied $24 \mathrm{~h}$ later. The cells were subjected to Western blot analyses after an additional $24 \mathrm{~h}$, and mitochondrial labeling or terminal deoxynucleotidyl transferase-mediated dUTP nick end labeling (TUNEL) assays were conducted.

\section{TUNEL assay}

The TUNEL assay was performed using NCI-H441 and RLE-6TN cells and the In Situ Cell Death Detection kit (Roche Applied Science, Upper Bavarie, Germany) according to the manufacturer's instructions [4]. Briefly, the cells were fixed with $4 \%$ paraformaldehyde, permeabilized with $0.1 \%$ Triton X-100 in $0.1 \%$ sodium citrate ( $\mathrm{pH}$ 7.4), and incubated with the TUNEL reaction mixture containing terminal deoxynucleotidyl transferase and FITC-labeled dUTP for $1 \mathrm{~h}$ at $37{ }^{\circ} \mathrm{C}$, followed by nuclear counterstaining with DAPI. The double-stained cells were observed through a fluorescence microscope (Axioskop 2 plus; Carl Zeiss, Oberkochen, Germany). A cell was deemed TUNEL-positive if it exhibited TUNEL signals among the DAPI nuclear stain. The number of TUNEL-positive cells was counted among 500 cells. In some experiments, FITC-labeled peptide-transfected NCIH441 and RLE-6TN cells were analyzed with a Click-iT Plus TUNEL Assay Kit containing an Alexa Flour 594conjugated secondary antibody (Molecular Probes, Eugene, OR, USA), as we described previously [17]. The number of TUNEL-positive cells was counted among 300 cells either FITC-positive or -negative. All measurements were performed in triplicate, and the mean and standard error of the proportion of TUNEL-positive cells were calculated for each experimental group. The TUNEL assays were repeated three times with similar results.

\section{Mitochondrial labeling}

Mitochondria were labeled with red fluorescence as described previously [4]. Briefly, cells were incubated in growth medium containing $200 \mathrm{nM}$ Mitotracker (Molecular Probes, Eugene, OR, USA) for $30 \mathrm{~min}$ and washed with PBS twice. Then, images of the stained cells were captured using a confocal laser microscope (LSM510 Meta; Carl Zeiss).

\section{Human samples}

Human lung tissues were obtained from patients diagnosed with lung cancer who underwent pulmonary lobectomy or segmentectomy at Hiroshima University Hospital (Hiroshima, Japan) between 2010 and 2013. All smokers were obliged to quit smoking $>1$ month before the surgery. Non-cancerous portions (approximately $2 \mathrm{~cm}^{3}$ ) of the surgical specimens were cut into two pieces immediately after the operation; one was fixed in $10 \%$ buffered formalin to prepare hematoxylin and eosin ( $\mathrm{H} \& \mathrm{E})$-stained tissue sections, and the other was frozen to prepare lung tissue lysates. When an H\&E-stained specimen was consistently diagnosed as emphysematous by two pathologists, the patient was included in the present study as an "emphysematous lung" case. In contrast, when the two pathologists consistently detected few pathological changes in an H\&E-stained specimen, the patient was included as a "normal lung" case. All patients provided written informed consent to participate in this study, and our institutional review board approved the experimental protocol (approval number, Eki-350). 


\section{Western blot analysis and immunoprecipitation}

Cultured cell pellets and frozen lung tissues were lysed in Tris-buffered saline ( $\mathrm{pH} 7.4$ ) containing $1 \%$ sodium dodecyl sulfate, $5 \mathrm{mM}$ ethylenediaminetetraacetic acid, and a protease inhibitor cocktail (Sigma-Aldrich). Insoluble components were removed by centrifugation, and the supernatant was used as a cell or lung tissue lysate. Western blot analyses were conducted, and

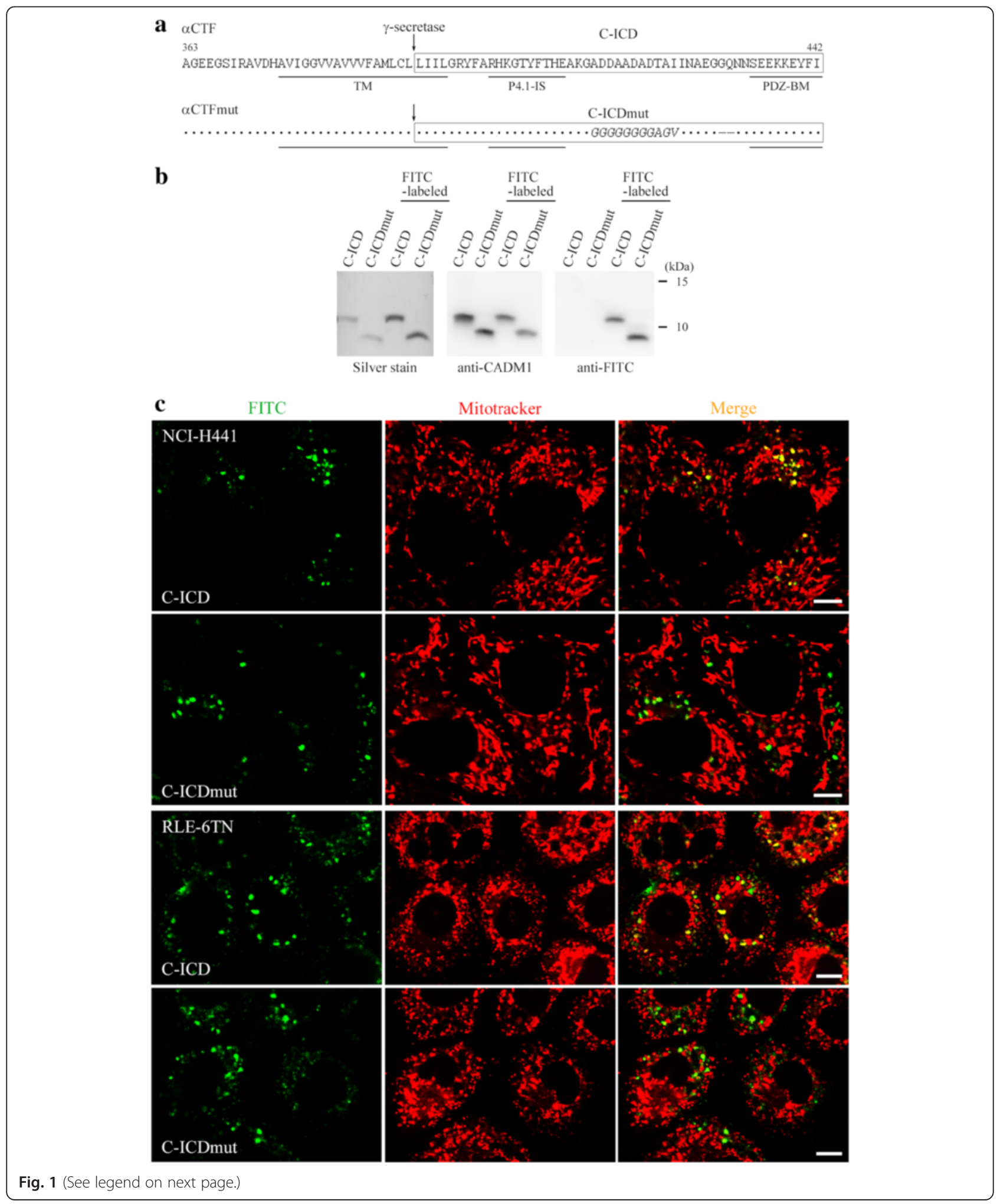


(See figure on previous page.)

Fig. 1 Mitochondrial localization of the cell adhesion molecule 1 intracellular domain (C-ICD) peptide in lung epithelial cell lines. a Full-length amino acid sequences of the a-C-terminal fragment (aCTF) and the aC-terminal fragment mutant (aCTFmut) of cell adhesion molecule 1. The C-ICD and the cell adhesion molecule 1 intracellular domain mutant (C-ICDmut) are shown in the boxed portions. The arrow indicates the $\gamma$-secretase cleavage site. Dots indicate the amino acid residues as above. The 7-amino acid substitution and the 2-amino acid deletion in C-ICDmut are shown in italics and -, respectively. The structural motifs are underlined. TM, transmembrane domain; P4.1-IS, protein 4.1 interaction sequence; PDZ-BM, PDZ type II domainbinding motif. Amino acid residues are numbered according to the NCBI database sequence (accession number, CCD32610). $\mathbf{b}$ The unlabeled and FITC-labeled C-ICD and C-ICDmut peptides were detected by sodium dodecyl sulfate polyacrylamide gel electrophoresis, and by silver staining (left) or Western blotting of the gels using antibodies against cell adhesion molecule 1 (CADM1) (middle) or FITC (right). c NCl-H441 (upper) and RLE-6TN (lower) cells were introduced with the FITC-labeled C-ICD or C-ICDmut peptide and stained with Mitotracker. Green (FITC) and red (Mitotracker) fluorescent images were merged, as shown in the right panels. Bar $=10 \mu \mathrm{m}$

immunoreactive band intensities were quantified using NIH ImageJ software, as described previously [18]. The lung lysates were diluted with PBS $(1: 9, \mathrm{v} / \mathrm{v})$ for immunoprecipitation, prior to adding the antiCADM1 antibody. The procedures were essentially the same as described in our past report [19].

\section{Rat primary cultured alveolar epithelial cells (AECs)}

Type 1 AECs were isolated from Sprague-Dawley rats, and were cultured to differentiate into type 2 AECs according to the published protocol [20]. Experiments with rats were performed in accordance with the Guide for Animal Experimentation of Kinki University (approval number, KAME-25-019).

\section{Reverse transcription (RT)-PCR}

The methods of RNA extraction, reverse transcription, and PCR to detect CADM1 isoforms were essentially identical to those described previously [16]. PCR primers for caveolin-1, a type 1 AEC marker, and surfactant protein $\mathrm{B}$, a type 2 AEC marker, were according to past studies [21, 22].

\section{Statistical analysis}

The proportions of TUNEL-positive cells were compared between the two groups using the Student's $t$-test. The number of patients expressing the C-ICD in lungs was assessed between the two groups using Fisher's exact test. A $P$-value $\leq 0.05$ was considered significant.

\section{Results}

The C-ICD peptide localizes to mitochondria and induces apoptosis in lung epithelial cells

We previously detected the C-ICD in lysates of COS7 cells that had been modified to overexpress CADM1, and we reported a presumed $\gamma$-secretase $\alpha$ CTF cleavage site [11]. According to the cleavage site, we chemically synthesized C-ICD as a 51-amino acid peptide. We also synthesized a 49-amino acid peptide (C-ICDmut) as a control by using the same cleavage site as $\alpha C T F m u t$, which carried seven amino acid substitutions and two amino acid deletions (Fig. 1a) [4]. Successful synthesis was confirmed by LC-MS/MS (Additional file 1: Figure S1).
The C-ICD and C-ICDmut peptides were detected at approximately 11 and $9 \mathrm{kDa}$ on a Western blot, respectively (Fig. 1b), although the theoretical molecular weight of the C-ICD peptide is $5.3 \mathrm{kDa}$ [11] (Fig. 1b). These peptides were introduced into NCI-H441 and RLE-6TN lung epithelial cells using Xfect reagents after FITC labeling. As peptide transduction efficacy was rather low, we conducted the Xfect treatment on identical cell cultures once daily for two consecutive days and stained the cells with Mitotracker dye, a mitochondrial marker, the next day. The FITClabeled C-ICD and C-ICDmut peptides were both detected as fine or coarse aggregates in the cytoplasm (Fig. 1c, left). Most of the C-ICD green signals turned yellow when the FITC and Mitotracker fluorescent images were merged, whereas the C-ICDmut signals remained green, indicating that the C-ICD signals preferentially colocalized with Mitotracker stain, whereas the C-ICDmut signals were not (Fig. 1c, right). Peptide transduction experiments were conducted on COS7 and NIH3T3 cells. The FITClabeled C-ICD and C-ICDmut peptides were detected as fine or coarse aggregates in the cytoplasm but did not colocalize with the Mitotracker stain (Additional file 2: Figure S2).

The C-ICD may induce apoptosis of lung epithelial cells by accumulating in mitochondria, as seen with $\alpha C T F$ [4]. To test this possibility, we used peptides without FITC labeling to prevent FITC from masking the proper actions of the peptides. The day after two Xfect treatments over two consecutive days, we analyzed the cells by Western blot analysis and TUNEL assays. Western blot analyses weakly but successfully detected the C-ICD and C-ICDmut peptides at roughly equal intensities in NCI-H441 and RLE-6TN cells (Fig. 2a). The proportions of TUNEL-positive cells were approximately $1 \%$ in both cell lines when left untreated or when introduced with the C-ICDmut peptide, whereas the proportions increased 2.3- and 5.1-fold in NCI-H441 and RLE-6TN cells, respectively, when introduced with the C-ICD peptide (Fig. 2b). Similar TUNEL assays were done on NCI-H441 and RLE6TN cells using the FITC-labeled C-ICD peptide. The proportion of TUNEL-positive cells reached to $7.8 \%$ in NCI-H441 cells positive for FITC (i.e., cells 


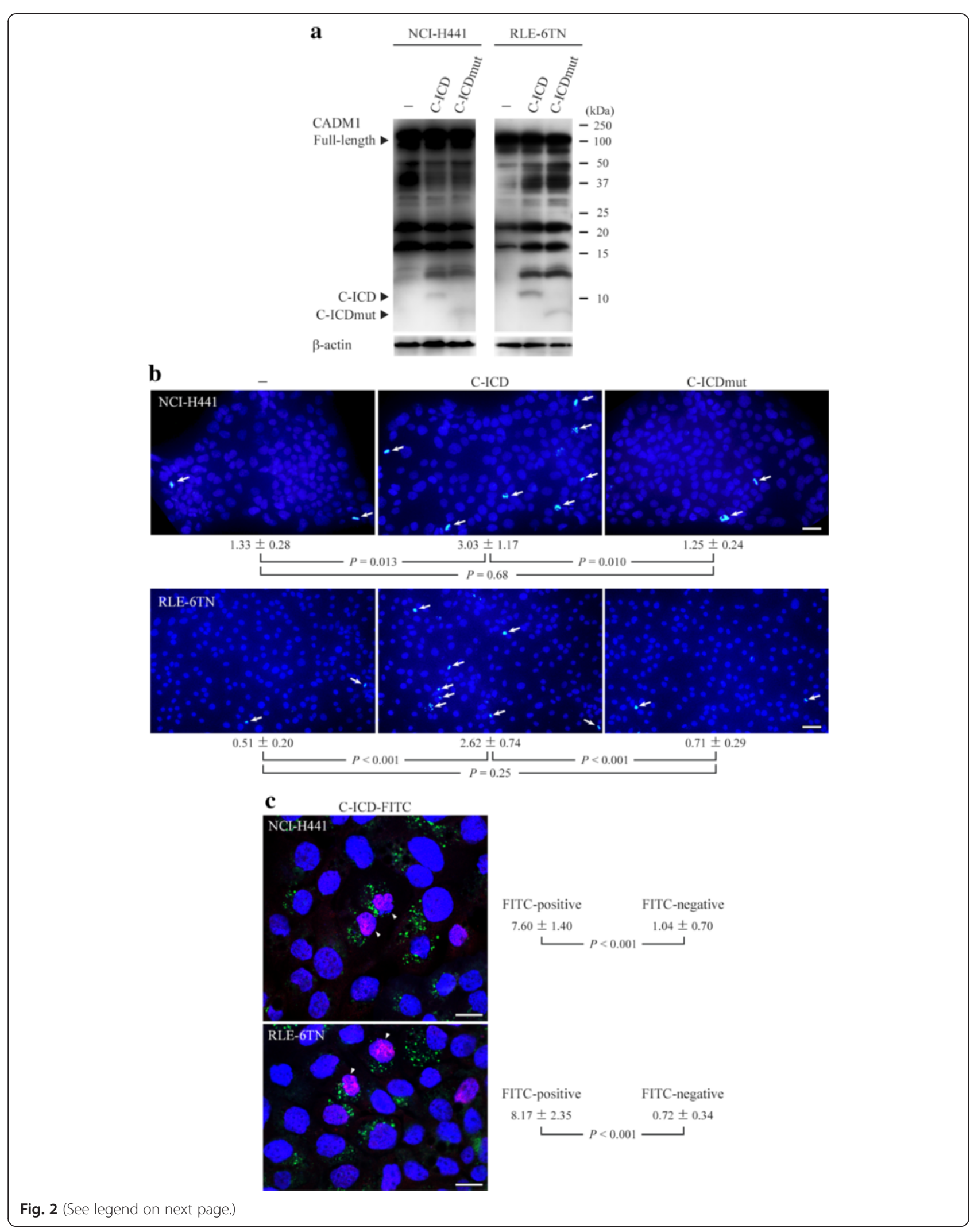


(See figure on previous page.)

Fig. 2 Induction of lung epithelial cell apoptosis by the cell adhesion molecule 1 intracellular domain (C-ICD) peptide. NCI-H441 and RLE-6TN cells were treated with Xfect solutions containing the unlabeled C-ICD or the cell adhesion molecule 1 intracellular domain mutant (C-ICDmut) peptide or were left untreated (-). The cells were analyzed the next day by Western blotting using anti-cell adhesion molecule 1 (CADM1) antibody (a). Arrowheads indicate immunoreactive bands corresponding to full-length CADM1, the C-ICD. The blots were reprobed with anti- $\beta$-actin antibody to indicate protein loading. Another set of cells was analyzed by terminal deoxynucleotidyl transferase-mediated dUTP nick end labeling (TUNEL) assay (b). The mean proportions of TUNEL-positive cells (depicted by arrows) and standard errors are indicated under the panels. The $P$-values were determined by Student s t-test. Bar $=50 \mu \mathrm{m}$. c Similar TUNEL assays were done using the FITC-labeled C-ICD peptide (C-ICD-FITC). The mean proportions of TUNEL-positive cells and standard errors were calculated in each of FITC-positive and -negative cells. Cells double positive for FITC and TUNEL are depicted by arrowheads. The P-values were determined by Student's $t$-test. Bar $=20 \mu \mathrm{m}$

containing the C-ICD peptide), whereas it was below $1 \%$ in FITC-negative cells (i.e., cells not containing the C-ICD peptide). Similar results were obtained with RLE-6TN cells (Fig. 2c).

\section{The abundance of C-ICD molecules is sparse but present in emphysematous lungs}

We obtained histologically normal $(n=4)$ and emphysematous $(n=4)$ lung tissues from patients who underwent lung lobectomy due to cancer. The patient characteristics are summarized in Table 1, and the lung histology is shown in Additional file 3: Figure S3. The tissue lysates were Western blotted using the CADM1 antibody. Consistent with our previous report [4], the quantity of $\alpha \mathrm{CTF}$ relative to full-length CADM1 increased in emphysematous lungs, but the quantity of C-ICD was below the detection limit (Fig. 3a). The lung lysates were then subjected to immunoprecipitation using the CADM1 antibody and Western blotting using the same antibody. All eight samples expressed full-length CADM1 as abundantly as in the original lysates, whereas the C-ICD was essentially undetectable in four normal lungs but certainly detectable in all four emphysematous lungs (Fig. 3b; 4/4 vs. $0 / 4, P=0.029)$. To confirm the molecular weight of the C-ICD, we used COS7 cells that overexpressed CADM1 exogenously, because we previously detected the C-ICD in the lysate of these cells by treatment with PMA, a shedding inducer [11]. Western blot analyses revealed that the

Table 1 Clinical characteristics of patients with normal and emphysematous lungs

\begin{tabular}{lllllllll}
\hline & \multicolumn{1}{l}{ Normal } & \multicolumn{4}{c}{ Emphysematous } \\
\hline Case & 1 & 2 & 3 & 4 & 5 & 6 & 7 & 8 \\
Age & 60 & 48 & 72 & 74 & 58 & 71 & 71 & 87 \\
Sex & $\mathrm{M}$ & $\mathrm{M}$ & $\mathrm{F}$ & $\mathrm{F}$ & $\mathrm{M}$ & $\mathrm{F}$ & $\mathrm{F}$ & $\mathrm{M}$ \\
Brinkman index & 800 & 0 & 0 & 0 & 370 & 0 & 0 & 2800 \\
Cause of surgery $^{\mathrm{a}}$ & $\mathrm{SQ}$ & $\mathrm{AD}$ & $\mathrm{AD}$ & $\mathrm{AD}$ & $\mathrm{AD}$ & $\mathrm{AD}$ & $\mathrm{AD}$ & $\mathrm{SQ}$ \\
Excised lung lobe $^{\mathrm{b}}$ & $\mathrm{LU}$ & $\mathrm{LL}$ & $\mathrm{RU}$ & $\mathrm{LL}$ & $\mathrm{LL}$ & $\mathrm{LU}$ & $\mathrm{RU}$ & $\mathrm{RU}$ \\
FEV1/FVC $^{\text {DLCO (\%) }}$ & $\mathrm{NE}$ & 83.1 & 74.6 & 71.2 & 77.3 & 73.4 & 80.5 & 71.5 \\
CLC $^{\mathrm{a}}$ & $\mathrm{NE}$ & $\mathrm{NE}$ & $\mathrm{NE}$ & $\mathrm{NE}$ & $\mathrm{NE}$ & $\mathrm{NE}$ & $\mathrm{NE}$ & 57.6 \\
\hline
\end{tabular}

${ }^{a} A D$ adenocarcinoma, $S Q$ squamous cell carcinoma

${ }^{\mathrm{b}} R U$ right upper, $R L$ right lower, $L U$ left upper, $L L$ left lower

${ }^{\mathrm{C}} N E$ not examined
C-ICD peptide was identical in molecular weight (approximately $11 \mathrm{kDa}$ ) to the C-ICD from the COS7 cell lysate (Additional file 4: Figure S4).

\section{Detection of CADM1 isoforms expressed in lung epithelial cells}

Because individual CADM1 isoforms have different properties [9], it is significant to determine which isoforms are expressed in lung epithelial cells. We isolated type 2 AECs from the rat lung, and cultured them to differentiate into type 1 AECs. Successful preparation of these primary cells was verified by RT-PCR analyses showing that type 1 and type 2 AECs had more mRNA for their

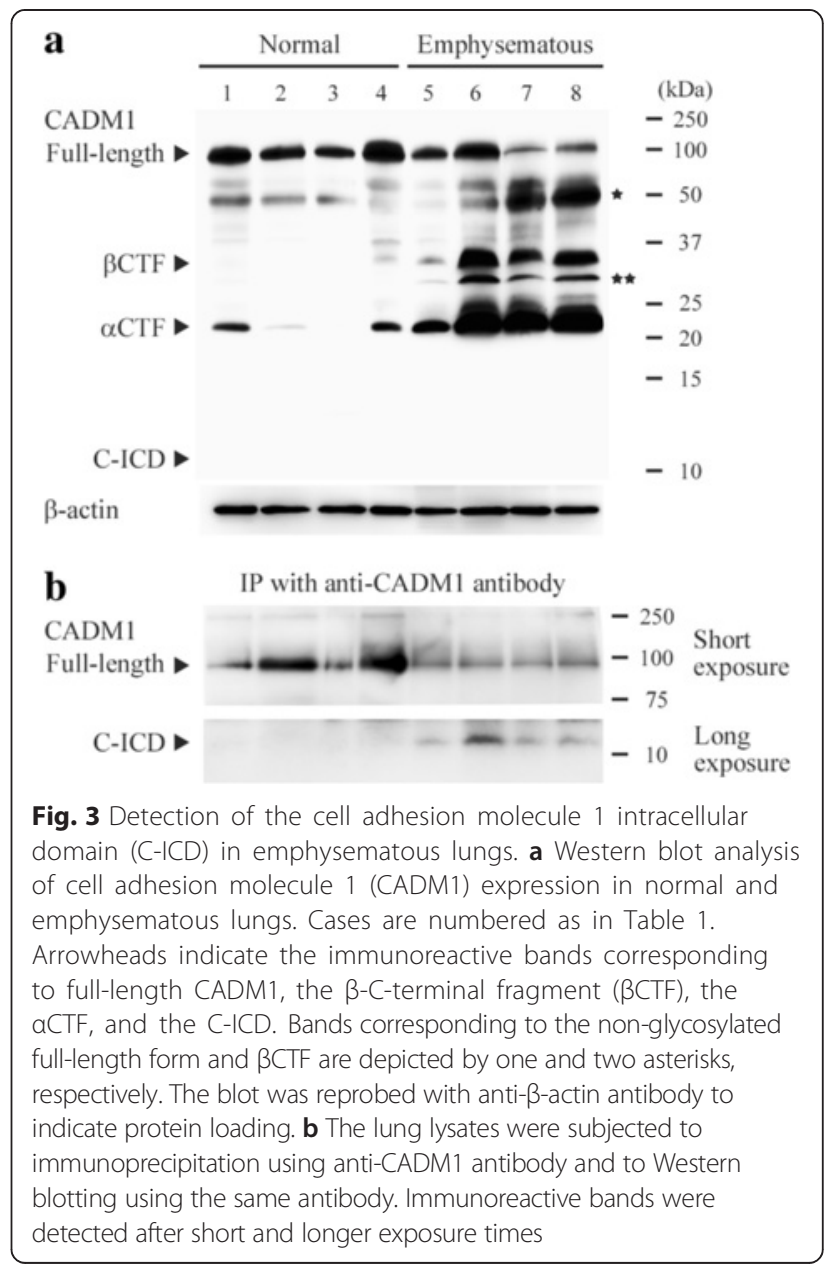


corresponding marker proteins, caveolin-1 [21] and surfactant protein B [22] (Fig. 4a). RT-PCR analyses to detect CADM1 mRNA revealed that SP4 was exclusively expressed in type 1 and type 2 AECs, two lung epithelial cell lines and human lung tissues examined in the present study (Fig. 4b).

\section{Discussion}

The C-ICD peptide was localized preferentially to mitochondria in NCI-H441 and RLE-6TN cells, but it was occasionally detected elsewhere. In addition, mitochondrial localization of the C-ICD appeared to depend on the cell type, because it was not observed in COS7 or NIH3T3 cells. These results are consistent with our previous notion that $\alpha \mathrm{CTF}$ lacks a canonical mitochondrial targeting sequence but is transported to mitochondria by binding to particular chaperones, such as heat shock proteins 40 and 90 [4, 23, 24]. Lung epithelial cells may express functional chaperones that efficiently transport cytosolic molecules to mitochondria.

Localization of the C-ICD in mitochondria appeared to result in the induction of apoptosis. Similar mechanisms have been suggested for other molecules. The adenomatous polyposis coli (APC) tumor suppressor is

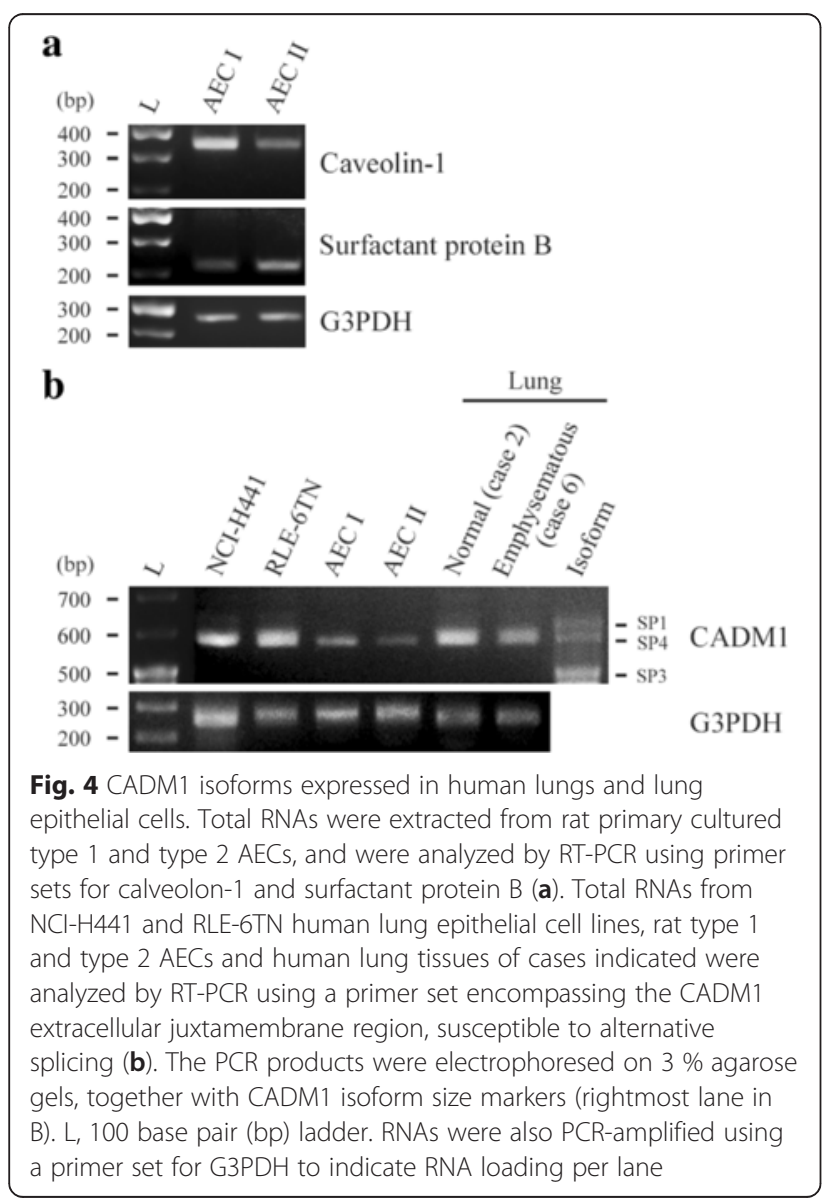

cleaved by caspase to release an $\mathrm{N}$-terminal 777 -amino acid fragment, which localizes to mitochondria and facilitates apoptosis [25, 26]. Transcription factor p53 and activating transcription factor two localize in mitochondria under genotoxic stress and depolarize the outer membrane potential [27-30]. Molecules that accumulate in the mitochondria as an alternative may accelerate already initiated apoptosis. Interestingly, the C-ICD is likely to accumulate in the mitochondrial intermembrane space because it is small enough to pass through the porin pores, in which a voltage-dependent anion channel protein spans the outer membrane [31, 32]. The intermembrane space has attracted attention as an organelle microdomain important for mitochondrial function, because it contains not only executioners of apoptosis, such as Smac and cytochrome $c$ [33], but also critical factors for the maintenance of mitochondrial dynamics and homeostasis, such as adenylate kinase and polynucleotide phosphorylase [33, 34]. Accumulation of the C-ICD in this space may perturb mitochondrial integrity and trigger depolarization of the outer membrane potential.

Ectodomain shedding of CADM1 is a prerequisite for generation of C-ICD [11]. Ectodomain cleavability varies among CADM1 isoforms; SP3 is non-cleavable, SP1 and SP2 are constitutively cleavable, and SP4 is inducibly cleavable by pathological stimuli $[11,35]$. As shown in Fig. 4, lung epithelial cells appeared to express SP4 exclusively. Therefore, C-ICD may be generated in lung epithelial cells under specific pathological conditions where SP4 ectodomain shedding is induced, such as emphysema and interstitial pneumonia [4, 17].

We showed that C-ICD molecules were sparse but present in emphysematous lungs, suggesting a contribution of this domain to the development of emphysema. This speculation needs detailed evaluation by future experiments using primary human lung epithelial cells and animal models. As the C-ICD is produced by $\gamma$-secretase, $\gamma$-secretase inhibitors may be effective at halting the progression of lung epithelial apoptosis in patients with emphysema. Various $\gamma$ secretase inhibitors have been developed as treatments for Alzheimer's disease, and some are currently under phase I - III preclinical evaluation [36, 37] and may be applicable to patients with emphysema. Our results deepen the understanding of emphysema pathogenesis and may open a new avenue for targetbased therapeutic approaches to the disease.

\section{Conclusions}

The C-ICD localized in mitochondria, induced apoptosis in lung epithelial cells, and was scarce in abundance but present in emphysematous lungs. Therefore, the C-ICD appears to contribute to the development and progression of pulmonary emphysema. 


\section{Additional files}

Additional file 1: Figure S1. Synthesis of the cell adhesion molecule 1 intracellular domain (C-ICD) and the mutated cell adhesion molecule 1 intracellular domain (C-ICDmut) peptides. High-performance liquid chromatography data of the synthesized peptides. The C-ICD (upper) and C-ICDmut (lower) peptides were detected at 5657.09 (theoretical value 5657.78 ) and 5127.55 (theoretical value 5126.57 ) $\mathrm{m} / \mathrm{z}$, respectively. (TIFF $356 \mathrm{~kb})$

Additional file 2: Figure S2. Subcellular localization of the intracellular domain (ICD) and the mutated intracellular domain (ICDmut) peptides in COS7 and NIH3T3 cells. COS7 (left) and NIH3T3 (right) cells were introduced with the FITC-labeled C-ICD (upper) or the C-ICDmut (lower) peptide and stained with Mitotracker. Green (FITC) and red (Mitotracker) fluorescent images were merged. Bar $=10 \mu \mathrm{m}$. (TIFF $1683 \mathrm{~kb}$ )

Additional file 3: Figure S3. Histology of normal and emphysematous lungs. Representative histological images of normal (case no.2) and emphysematous (case no.7) lungs are shown in the left and right panels, respectively. Hematoxylin and eosin stain. Bar $=100 \mu \mathrm{m}$. (TIFF $4669 \mathrm{~kb}$ )

Additional file 4: Figure S4. Detection of the cell adhesion molecule 1 intracellular domain (C-ICD) and C-ICD peptide by Western blot analysis. Original COS7 and CADM1-overexpressing COS7 (COS7-CADM1) cells were left untreated $(-)$ or treated with PMA $(200 \mathrm{ng} / \mathrm{ml} ;+)$. These cell lysates and the solutions containing the C-ICD or mutant C-ICD (C-ICDmut) peptides were analyzed by Western blotting using anti-cell adhesion molecule 1 (CADM1) antibody. Immunoreactive bands were detected after short and longer exposure times. The blot was reprobed with anti- $\beta$-actin antibody to indicate protein loading. Arrowheads indicate immunoreactive bands corresponding to the various forms of CADM1 and peptides named. (TIFF $142 \mathrm{~kb}$ )

\section{Abbreviations}

C-ICD: Cell adhesion molecule 1 intracellular domain; C-ICDmut: Mutant form of C-ICD; CADM1: Cell adhesion molecule 1; CTF: C-terminal fragment; FITC: Fluorescein isothiocyanate; H\&E: Hematoxylin and eosin; ICD: Intracellular domain; P4.1-IS: Protein 4.1 interaction sequence; PDZ-BM: PDZ type II domain-binding motif; TUNEL: Terminal deoxynucleotidyl transferase-mediated dUTP nick end labeling.

\section{Competing interests}

The authors declare that they have no competing interests.

\section{Authors' contributions}

$\mathrm{MH}$ and $\mathrm{AY}$ carried out the Western blotting and cell fluorescence experiments, and $\mathrm{MH}$ performed the statistical analysis. TI and YS participated in the Western blotting and cell fluorescence experiments, respectively. TM and MO provided the human samples and performed the histological examination. Al conceived and designed the study, carried out the histological examination, and drafted the manuscript. All authors have read and approved the final manuscript.

\section{Acknowledgements}

The authors thank Eiko Honda, Shoei Sakata, Yoshihiro Mine, and Takuya Wada (Central Research Facilities, Faculty of Medicine, Kinki University) for their technical assistance. This study was supported by the Japan Society for the Promotion of Science Kakenhi (26860267 to AY, 25860302 to $\mathrm{MH}$, and 24590492 to $\mathrm{Al}$ ).

\section{Author details}

${ }^{1}$ Department of Pathology, Faculty of Medicine, Kinki University, Osaka 589-8511, Japan. ${ }^{2}$ Department of Surgical Oncology, Research Institute for Radiation Biology and Medicine, Hiroshima University, Hiroshima, Japan.

Received: 16 April 2015 Accepted: 30 July 2015

Published online: 11 August 2015

\section{References}

1. Snider GL, Kleinerman J, Thurlbeck WM, Bengali ZH. The definition of emphysema. Report of a National Heart, Lung, and Blood Institute, Division of Lung Diseases workshop. Am Rev Respir Dis. 1985;132:182-5.

2. Tuder RM, Petrache I, Elias JA, Voelkel NF, Henson PM. Apoptosis and emphysema: the missing link. Am J Respir Cell Mol Biol. 2003;28(5):551-4. doi:10.1165/rcmb.F269.

3. Taraseviciene-Stewart $\mathrm{L}$, Voelkel NF. Molecular pathogenesis of emphysema. J Clin Invest. 2008;118(2):394-402. doi:10.1172/JCl31811.

4. Mimae $T$, Hagiyama M, Inoue $T$, Yoneshige $A$, Kato $T$, Okada M, et al. Increased ectodomain shedding of lung epithelial cell adhesion molecule 1 as a cause of increased alveolar cell apoptosis in emphysema. Thorax. 2014;69(3):223-31. doi:10.1136/thoraxjnl -2013-203867.

5. Kuramochi M, Fukuhara $H$, Nobukuni $T$, Kanbe $T$, Maruyama T, Ghosh HP, et al. TSLC1 is a tumor-suppressor gene in human non-small-cell lung cancer. Nat Genet. 2001;27(4):427-30. doi:10.1038/86934.

6. Moiseeva EP, Roach KM, Leyland ML, Bradding P. CADM1 is a key receptor mediating human mast cell adhesion to human lung fibroblasts and airway smooth muscle cells. PLoS One. 2013;8(4):e61579. doi:10.1371/journal.pone.0061579.

7. Ito A, Okada M, Uchino K, Wakayama T, Koma Y, Iseki S, et al. Expression of the TSLC1 adhesion molecule in pulmonary epithelium and its down-regulation in pulmonary adenocarcinoma other than bronchioloalveolar carcinoma. Lab Investig. 2003;83(8):1175-83.

8. Biederer T, Sara Y, Mozhayeva M, Atasoy D, Liu X, Kavalali ET, et al. SynCAM, a synaptic adhesion molecule that drives synapse assembly. Science. 2002;297(5586):1525-31. doi:10.1126/science.1072356.

9. Moiseeva EP, Leyland ML, Bradding P. CADM1 isoforms differentially regulate human mast cell survival and homotypic adhesion. Cell Mol Life Sci. 2012;69(16):2751-64. doi:10.1007/s00018-012-0948-y.

10. Fogel Al, Li Y, Giza J, Wang Q, Lam T, Modis Y, et al. N-glycosylation at the SynCAM (synaptic cell adhesion molecule) immunoglobulin interface modulates synaptic adhesion. J Biol Chem. 2010;285(45):34864-74. doi:10.1074/jbc.M110.120865.

11. Nagara Y, Hagiyama M, Hatano N, Futai E, Suo S, Takaoka Y, et al. Tumor suppressor cell adhesion molecule 1 (CADM1) is cleaved by a disintegrin and metalloprotease 10 (ADAM10) and subsequently cleaved by gamma-secretase complex. Biochem Biophys Res Commun. 2012;417(1):462-7. doi:S0006-291X(11)02168-1.

12. Kim DY, Ingano LA, Kovacs DM. Nectin-1alpha, an immunoglobulin-like receptor involved in the formation of synapses, is a substrate for presenilin/ gamma-secretase-like cleavage. J Biol Chem. 2002;277(51):49976-81. doi:10.1074/jbc.M210179200.

13. Greenwald I. Notch and the awesome power of genetics. Genetics. 2012;191(3):655-69. doi:10.1534/genetics.112.141812..

14. Koma Y, Ito A, Wakayama T, Watabe K, Okada M, Tsubota N, et al. Cloning of a soluble isoform of the SgIGSF adhesion molecule that binds the extracellular domain of the membrane-bound isoform. Oncogene. 2004;23(33):5687-92. doi:10.1038/sj.onc.1207761.

15. Ito A, Jippo T, Wakayama T, Morii E, Koma Y, Onda H, et al. SgIGSF: a new mast-cell adhesion molecule used for attachment to fibroblasts and transcriptionally regulated by MITF. Blood. 2003;101(7):2601-8. doi:10.1182/blood-2002-07-2265.

16. Hagiyama M, Ichiyanagi N, Kimura KB, Murakami $Y$, Ito A. Expression of a soluble isoform of cell adhesion molecule 1 in the brain and its involvement in directional neurite outgrowth. Am J Pathol. 2009;174(6):2278-89. doi:S0002-9440(10)61086-3.

17. Yoneshige A, Hagiyama,M., Inoue, T., Mimae, T., Kato T., Okada, M., Enoki, E. Ito, A. Increased ectodomain shedding of cell adhesion molecule 1 as a cause of type II alveolar epithelial cell apoptosis in patients with idiopathic interstitial pneumonia. Respir Res. in press.

18. Mimae $T$, Okada M, Hagiyama M, Miyata $Y$, Tsutani $Y$, Inoue $T$, et al. Upregulation of notch2 and six 1 is associated with progression of early-stage lung adenocarcinoma and a more aggressive phenotype at advanced stages. Clin Cancer Res. 2012;18(4):945-55. doi:10.1158/1078-0432.CCR-11-1946.

19. Ito A, Kataoka TR, Watanabe M, Nishiyama K, Mazaki Y, Sabe H, et al. A truncated isoform of the PP2A B56 subunit promotes cell motility through paxillin phosphorylation. EMBO J. 2000;19(4):562-71. doi:10.1093/emboj/19.4.562. 
20. Ikehata M, Yumoto R, Nakamura K, Nagai J, Takano M. Comparison of albumin uptake in rat alveolar type II and type I-like epithelial cells in primary culture. Pharm Res. 2008;25(4):913-22. doi:10.1007/s11095-007-9426-X.

21. Koslowski R, Barth K, Augstein A, Tschernig T, Bargsten G, Aufderheide M, et al. A new rat type I-like alveolar epithelial cell line R3/1: bleomycin effects on caveolin expression. Histochem Cell Biol. 2004;121(6):509-19. doi:10.1007/s00418-004-0662-4.

22. Chen CM, Wang LF, Yeh TF. Effects of maternal nicotine exposure on lung surfactant system in rats. Pediatr Pulmonol. 2005;39(2):97-102. doi:10.1002/ ppul.20122.

23. Ren J, Bharti A, Raina D, Chen W, Ahmad R, Kufe D. MUC1 oncoprotein is targeted to mitochondria by heregulin-induced activation of c-Src and the molecular chaperone HSP90. Oncogene. 2006;25(1):20-31. doi:1209012.

24. Maiti P, Manna J, Veleri S, Frautschy S. Molecular chaperone dysfunction in neurodegenerative diseases and effects of curcumin. Biomed Res Int. 2014;2014:495091. doi:10.1155/2014/495091.

25. Qian J, Steigerwald K, Combs KA, Barton MC, Groden J. Caspase cleavage of the APC tumor suppressor and release of an amino-terminal domain is required for the transcription-independent function of APC in apoptosis. Oncogene. 2007;26(33):4872-6. doi:1210265.

26. Qian J, Perchiniak EM, Sun K, Groden J. The mitochondrial protein hTID-1 partners with the caspase-cleaved adenomatous polyposis cell tumor suppressor to facilitate apoptosis. Gastroenterology. 2010;138(4):1418-28. doi:S0016-5085(09)01941-6.

27. Marchenko ND, Zaika A, Moll UM. Death signal-induced localization of p53 protein to mitochondria. A potential role in apoptotic signaling. J Biol Chem. 2000:275(21):16202-12. doi:275/21/16202.

28. Mihara M, Erster S, Zaika A, Petrenko O, Chittenden T, Pancoska P, et al. p53 has a direct apoptogenic role at the mitochondria. Mol Cell. 2003;11(3):577-90. doi:S1097276503000509.

29. Bhoumik A, Huang TG, Ivanov V, Gangi L, Qiao RF, Woo SL, et al. An ATF2-derived peptide sensitizes melanomas to apoptosis and inhibits their growth and metastasis. J Clin Invest. 2002;110(5):643-50. doi:10.1172/ JCl16081.

30. Bhoumik A, Jones N, Ronai Z. Transcriptional switch by activating transcription factor 2-derived peptide sensitizes melanoma cells to apoptosis and inhibits their tumorigenicity. Proc Natl Acad Sci U S A. 2004;101(12):4222-7. doi:10.1073/pnas.0400195101.

31. Colombini M. Pore size and properties of channels from mitochondria isolated from Neurospora crassa. J Membr Biol. 1980;53:79-84.

32. Krasilnikov OV, Sabirov RZ, Ternovsky VI, Merzliak PG, Muratkhodjaev JN. A simple method for the determination of the pore radius of ion channels in planar lipid bilayer membranes. FEMS Microbiol Immunol. 1992;5(1-3):93-100.

33. Herrmann JM, Riemer J. The intermembrane space of mitochondria. Antioxid Redox Signal. 2010;13(9):1341-58. doi:10.1089/ars.2009.3063.

34. Chen HW, Rainey RN, Balatoni CE, Dawson DW, Troke JJ, Wasiak S, et al. Mammalian polynucleotide phosphorylase is an intermembrane space RNase that maintains mitochondrial homeostasis. Mol Cell Biol. 2006;26(22):8475-87. doi:MCB.01002-06.

35. Tanabe Y, Kasahara T, Momoi T, Fujita E. Neuronal RA175/SynCAM1 isoforms are processed by tumor necrosis factor-alpha-converting enzyme (TACE)/ ADAM17-like proteases. Neurosci Lett. 2008;444(1):16-21. doi:S0304-3940(08)01111-7.

36. Kreft AF, Martone R, Porte A. Recent advances in the identification of gamma-secretase inhibitors to clinically test the Abeta oligomer hypothesis of Alzheimer's disease. J Med Chem. 2009;52(20):6169-88. doi:10.1021/ jm900188z.

37. Martone RL, Zhou H, Atchison K, Comery T, Xu JZ, Huang X, et al. Begacestat (GSI-953): a novel, selective thiophene sulfonamide inhibitor of amyloid precursor protein gamma-secretase for the treatment of Alzheimer's disease. J Pharmacol Exp Ther. 2009;331(2):598-608. doi:10.1124/ jpet.109.152975.

\section{Submit your next manuscript to BioMed Central and take full advantage of:}

- Convenient online submission

- Thorough peer review

- No space constraints or color figure charges

- Immediate publication on acceptance

- Inclusion in PubMed, CAS, Scopus and Google Scholar

- Research which is freely available for redistribution

Submit your manuscript at www.biomedcentral.com/submit 